\title{
Acetaldehyde and parkinsonism: role of CYP450 2E1
}

\author{
Francesca Vaglini *, Cristina Viaggi, Valentina Piro, Carla Pardini, Claudio Gerace, Marco Scarselli \\ and Giovanni Umberto Corsini
}

Department of Translational Research and New Technology in Medicine, University of Pisa, Pisa, Italy

\section{Edited by:}

Merce Correa, Universitat Jaume,

Spain

\section{Reviewed by:}

Merce Correa, Universitat Jaume, Spain

John D. Salamone, University of Connecticut, USA

\section{*Correspondence:}

Francesca Vaglini, Department of Translational Research and New

Technology in Medicine, University of Pisa, Via Roma 55, Pisa 56126,

Italy

e-mail: francesca.vaglini@

med.unipi.it
The present review update the relationship between acetaldehyde (ACE) and parkinsonism with a specific focus on the role of P450 system and CYP 2E1 isozyme particularly. We have indicated that ACE is able to enhance the parkinsonism induced in mice by 1-methyl-4-phenyl-1,2,3,6-tetrahydropyridine, a neurotoxin able to damage the nigrostriatal dopaminergic pathway. Similarly diethyldithiocarbamate, the main metabolite of disulfiram, a drug widely used to control alcoholism, diallylsulfide (DAS) and phenylisothiocyanate also markedly enhance the toxin-related parkinsonism. All these compounds are substrate/inhibitors of CYP450 2E1 isozyme. The presence of CYP 2E1 has been detected in the dopamine (DA) neurons of rodent Substantia Nigra (SN), but a precise function of the enzyme has not been elucidated yet. By treating CYP 2E1 knockout (KO) mice with the neurotoxin 1-methyl-4-phenyl-1,2,3,6-tetrahydropyridine, the SN induced lesion was significantly reduced when compared with the lesion observed in wild-type animals. Several in vivo and in vitro studies led to the conclusion that CYP 2E1 may enhance the 1-methyl-4-phenyl-1,2,3,6-tetrahydropyridine toxicity in mice by increasing free radical production inside the dopaminergic neurons. ACE is a good substrate for CYP 2E1 enzyme as the other substrate-inhibitors and by this way may facilitate the susceptibility of dopaminergic neurons to toxic events. The literature suggests that ethanol and/or disulfiram may be responsible for toxic parkinsonism in human and it indicates that basal ganglia are the major targets of disulfiram toxicity. A very recent study reports that there are a decreased methylation of the CYP 2E1 gene and increased expression of CYP 2E1 mRNA in Parkinson's disease (PD) patient brains. This study suggests that epigenetic variants of this cytochrome contribute to the susceptibility, thus confirming multiples lines of evidence which indicate a link between environmental toxins and PD.

Keywords: CYP450 2E1 isozyme, acetaldehyde, Parkinson's disease, dopaminergic neurons, ethanol

\section{ALCOHOL CONSUMPTION AND PARKINSON'S DISEASE}

A large number of case-control studies analysed the relationship between Parkinson's disease (PD) and some environmental factors (De Lau et al., 2004). Addictive behaviors, such as cigarette smoking and coffee drinking, showed a protective effect against PD and parkinsonism. Regarding alcohol consumption, most studies report either a moderately decreased risk or no change in risk associated with alcohol intake (Benedetti et al., 2000; Paganini-Hill, 2001; Hernan et al., 2004; Wirdefeldt et al., 2011; Campdelacreu, 2012; Noyce et al., 2012; Palacios et al., 2012). In contrast with these clinical findings, experimental data in rodents showed that alcohol induces a reduction in the dopamine (DA) levels in the midbrain, even if contradictory data are present in literature and an increased oxidative stress in nigral cells (Collins, 2002; Ambhore et al., 2012) and Golgi fragmentation (Tomas et al., 2012). Likely, alcohol consumption and neurodegenerative disease (e.g., PD) induce similar effects on intracellular structures and trafficking (Ambhore et al., 2012). It's conceivable that some components of alcoholic beverages (e.g., flavonoids in red wine) could have a neuroprotective activity (Palacios et al., 2012). Beer drinkers have a lower risk of PD (Hernan et al., 2003), and this result can be explained with higher plasma urate levels that beer induces. Indeed, urate plays a protective role against PD (Xiang et al., 2008). It has been known that in parkinsonian patients addiction such as cigarette smoking, drug consumption, alcoholism and compulsive disorders such as gambling, compulsive shopping, hypersexuality are less common than into general population (De Lau et al., 2004; Xiang et al., 2008; Noyce et al., 2012). Data collected in the last decades all over the world highlight the link between dopaminergic replacement and onset of addiction behaviors and compulsive disorders in Parkinson's patients (Villa et al., 2011). However, alcohol consumption and a history of alcoholism seem to be related with higher incidence of impulse control disorders in PD patients receiving dopaminergic replacement (Evans et al., 2005; Wu et al., 2009). Some endogenous alkaloids, like salsolinol (1-methyl-6,7-dihydroxy1,2,3,4-tetrahydroisoquinoline,SAL) and tetrahydropapaveroline (6,7 - dihydroxy - 1 - (3', $4^{\prime}$ - dihydroxybenzyl) - 1,2,3,4 - tetrahydroisoquinoline; THP), whose blood levels are increased by alcohol, have neurotoxic effects especially in the striatum and reduce DA content into basal ganglia (Young-Joon and Hyun-Jung, 2010). THP is detected at a high level in the urine of parkinsonian patients under L-DOPA therapy (Cashaw, 1993); however, there are very low levels of THP in the 
urine of abstinent alcoholics. Possible implications of THP in alcohol dependence were inferred from the observation that rats which normally rejected alcohol, would drink alcohol in excessive amount following direct delivery of THP (Duncan and Deitrich, 1980). Thus, these substances might contribute to alcohol dependence (Collins, 2004; Hipólito et al., 2012; Deehan et al., 2013). These factors can be useful to identify PD patients at high risk of developing impulse control disorders during dopaminergic replacement.

\section{ACETALDEHYDE AND PARKINSON'S DISEASE}

Acetaldehyde (ACE) is the alcohol metabolite responsible for unpleasant effects such as nausea, vomiting, tachycardia and hypotension. ACE increases the toxic effect of 1-methyl-4-phenyl1,2,3,6-tetrahydropyridine (MPTP) in striatum (Corsini et al., 1987; Zuddas et al., 1989a,b, 1992; Vaglini et al., 1996); this activity has been demonstrated in mice but not in rats (Fornai et al., 1997). There are no studies in humans that relate ACE to PD or parkinsonism, most likely because it's not a substance of abuse nor a drug nor a pollutant. ACE is further metabolized to acetic acid with catalysis of Aldehyde dehydrogenase (ALDH); disulfiram, a blocker of this enzyme, induces ACE accumulation and is used in treatment of alcoholism. Disulfiram can have a neurotoxic effect; namely, acute intoxication induces unilateral pallidal lesion as described by means of magnetic resonance evaluation and clinical assessment (De Mari et al., 1993) while chronic administration can induce Wernicke's encephalopathy, with progressive frontal decline and akineto-rigid parkinsonism (Charles et al., 2006). Brain MRI revealed symmetrical and reversible lesions in basal ganglia, but after discontinuation of disulfiram, clinical recovery was slow and partial. These observations suggest that basal ganglia are the major targets of disulfiram neurotoxicity (Laplane et al., 1992). Similar brain lesions are also observed in "energy deprivation syndromes," which are toxic, genetic or nutritional disorders that disrupt enzymes involved in energy production pathways (Laplane et al., 1992; Charles et al., 2006). Probably, disulfiram impairs cellular processes involved in ATP production but the exact mechanism remains unclear. It's conceivable that disulfiram toxicity is linked at least in part to the action of ACE; indeed other aldehydes, such as 3,4dihydroxyphenilacetaldehyde (DOPALD), an oxidative metabolite of DA, have been shown to have a neurotoxic activity (Gesi et al., 2001) and higher levels of these compounds are related with neurodegenerative diseases (Marchitti et al., 2007) (Figure 1).

\section{ACETALDEHYDE AND EXPERIMENTAL PARKINSONISM}

Corsini et al. (1985) unexpectedly found that diethyldithiocarbamate (DDC), the main metabolite of disulfiram, markedly enhanced the MPTP-induced parkinsonism in mice. This effect was initially interpreted as due to the inhibition of superoxide dismutase leading to an increase in oxidative stress induced by the toxin. Subsequently, among numerous compounds tested, other enhancers of MPTP toxicity (ethanol and ACE) were found by the same authors (Corsini et al., 1987). After this further discovery, this group suggested that these compounds could increase the potency of the toxin via an inhibition of ALDH within the striatum. The "enhancers," at the same time, prolonged the striatal half-life of 1-methyl-4-phenylpyridinium ion $\left(\mathrm{MPP}^{+}\right)$, the toxic metabolite of MPTP, (Irwin et al., 1987; Zuddas et al., 1989b) and this was interpreted as the causative factor of this enhancement. However, in 1996 an article by Vaglini et al. demonstrated that striatal $\mathrm{MPP}^{+}$levels do not necessarily correlate with MPTP toxicity in the same animal species (mouse) and they further on suggested, as previously reported, that DDC-increased toxicity was probably due to an independent action on glutamate receptors (Vaglini et al., 1996). However it is likely that the prolonged storage of $\mathrm{MPP}^{+}$inside the DA neurons was crucial for its toxic effects. According to this interpretation, the enzymes, which may

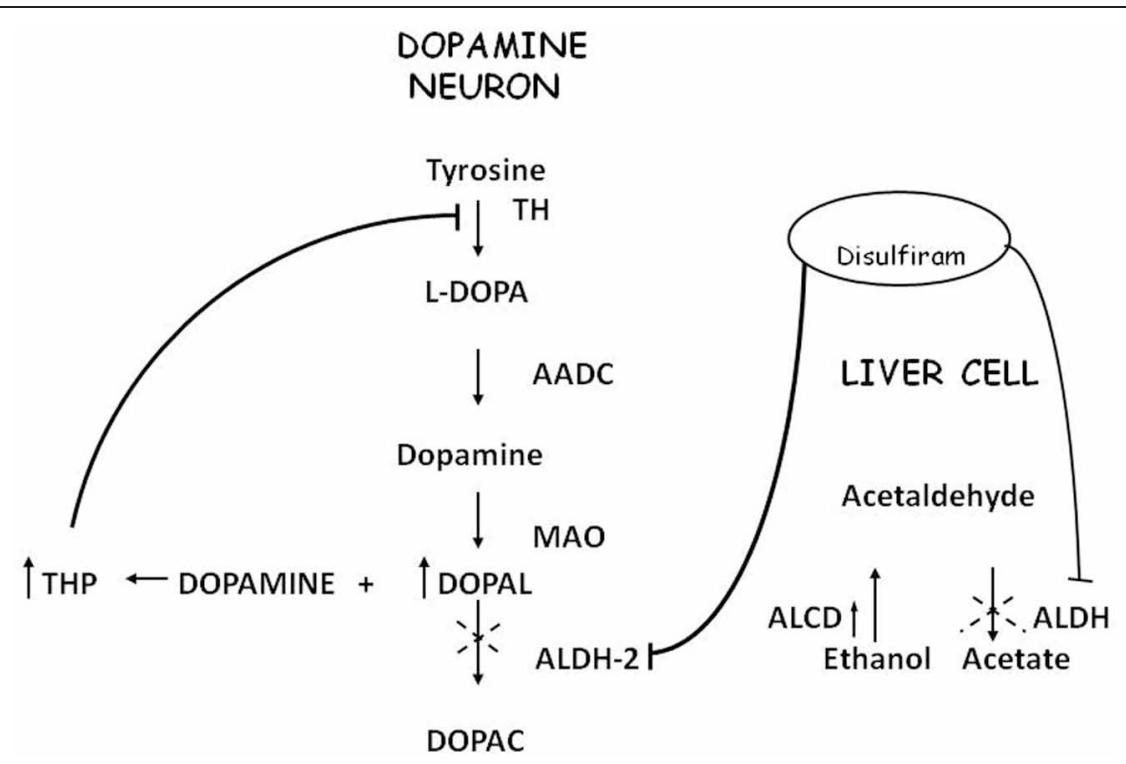

FIGURE 1 | Convergence of metabolic pathway for acetaldehyde and dopamine. 
determine the disposition of $\mathrm{MPP}^{+}$inside the DA neurons, have a cardinal role in MPTP toxicity. CYP 2E1 and the CYP 2D family are the most widely represented isozymes within the DA neurons (Watts et al., 1998; Riedl et al., 1999) and it is likely that these two $\mathrm{P} 450$ enzymes are responsible for $\mathrm{MPP}^{+}$clearance. As a matter of fact, DDC, ethanol and ACE have been discovered to be specific substrates/inhibitors of CYP 2E1 when they are acutely administered (Stott et al., 1997) (Figure 2). This specific inhibition inside the DA neuron may account for the increase in $\mathrm{MPP}^{+}$ striatal half-life, and thus toxicity.

More recently, furthermore, we demonstrated that, similar to DDC and ACE, CYP 2E1 substrates/inhibitors, such as diallylsulfide (DAS) or phenylethylisothiocyanate (PIC) markedly enhance MPTP toxicity in C57/bl brain, suggesting an involvement of CYP $2 \mathrm{E} 1$ in the enhancement of MPTP toxicity. However, because DAS and PIC are not true CYP 2E1 inhibitors (Nissbrandt et al., 2001), in order to provide direct evidence for CYP 2E1 involvement, CYP $2 \mathrm{E} 1$ knockout $(\mathrm{KO})$ mice and their wild-type counterparts were challenged with the combined treatment DDC+MPTP (Vaglini et al., 2004). In that article we consistently showed that an inhibition of the enzyme, as obtained with DDC challenge, failed to enhance the toxic effect of MPTP in CYP 2E1 KO mice, whereas the effect was regularly present in wild-type animals. Focusing on this, we have studied the sensitivity of CYP 2E1 KO mice to the toxin (Viaggi et al., 2009). The lack of CYP2 E1 did not increase MPTP toxicity as expected from previous experiments with the inhibitors, and, in fact, the CYP 2E1 KO mice showed a significant resistance to DA neuronal lesions induced by the toxin in comparison with their wild-type counterparts. The reduced sensitivity to MPTP of CYP 2E1 KO mice, but not the complete insensitivity, may be due to compensatory mechanisms taking place because of the missing protein. This phenomenon was observed very clearly by Gonzalez when his team generated these mice in order to study acetaminophen-induced liver toxicity (Lee et al., 1996). This drug causes liver and kidney necrosis when it is metabolized to an alkylating intermediate by the P450 system, and more specifically by CYP 2E1 (Jollow et al., 1973; Mitchell et al., 1973; Gonzalez, 2007). CYP 2E1 KO mice were generated to strengthen the specific role of CYP 2E1 during acetaminophen toxicity (Lee et al., 1996). The CYP 2E1 KO mice were less sensitive to the hepatotoxicity of the drug but they were not completely unaffected. A compensatory isozyme of the P450, probably CYP2D6, was substituted, thus producing the same-though reduced-toxic effect. Very recently we generated mesencephalic cell cultures from CYP 2E1 KO and wild-type embryos to investigate $\mathrm{MPP}^{+}$toxicity and its cell distribution. In this model we demonstrated that a trace amount of $\mathrm{MPP}^{+}$accumulates inside the neurons from $\mathrm{KO}$ mesencephalic cultures in a quantity double than that from wild-type embryos, although the $\mathrm{KO}$ cultures are less lesioned by the toxin (manuscript in preparation). We then suggested, once inside the cell (or striatal synaptic terminal), $\mathrm{MPP}^{+}$entered preferentially into vesicles where its storage represented a sort of protection with respect to other toxic sites such as mitochondria.

In conclusion CYP 2E1 may facilitate the transfer of $\mathrm{MPP}^{+}$to mitochondria for further metabolism. Alternatively and independently from $\mathrm{MPP}^{+}$disposition, CYP 2E1 produces toxic reactive intermediates from endogenous or exogenous substrates which in turn impair neuronal viability.

\section{THE P450 SYSTEM IN PD}

In 1985, Barbeau et al. elegantly presented evidence for an association of a CYP 2D6 defect with PD (Barbeau et al., 1985). Indeed, they postulated that subjects with a reduced CYP 2D6 enzyme (poor metabolizers) are vulnerable for PD because of the impaired capacity of liver to detoxify those neurotoxins which are harmful for DA neurons. It is worth noting that further studies have actually indicated CYP 2D6 as the major detoxifying liver enzyme for the PD-inducing neurotoxin, MPTP (Coleman et al., 1996; Gilham et al., 1997). After this pioneering report, however, many conflicting results were obtained in phenotypic and genotypic CYP 2D6 studies, which have been outlined in a comprehensive review by Riedl et al. (1998).

Several enzymes involved in the metabolism of endogenous compounds and xenobiotics have been studied in relation to PD. However, CYP450 in particular drew attention, due to its ability to defend the body against xenobiotic aggression. In particular, six P450 enzymes have been examined with respect to PD: CYP 1A1 (Kurth and Kurth, 1993; Bennet et al., 1994; Takakubo et al., 1996), CYP 2C9 (Ferrari et al., 1990; Peeters

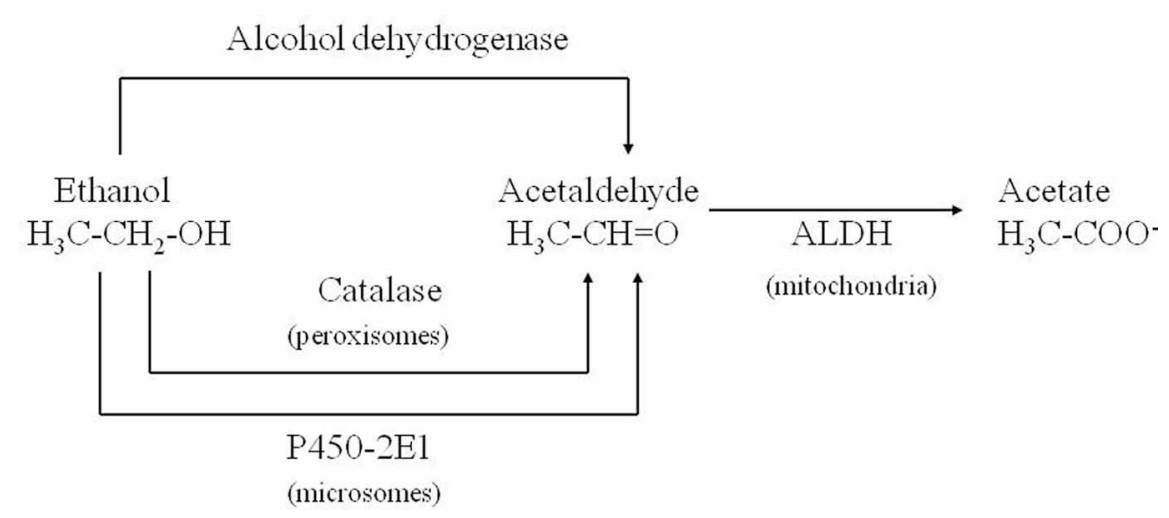

FIGURE 2 | Role of CYP 2E1 in metabolizing ethanol and acetaldehyde. 
et al., 1994), CYP 2C19 (Gudjonsson et al., 1990; Tsuneoka et al., 1996), CYP 1A2, CYP 2E1 (Factor et al., 1989; Steventon et al., 1989), and CYP 2D6 (Riedl et al., 1998). Since the first enthusiastic claim, more than 50 reports have debated the role of CYP 2 D6 in the pathogenesis of PD. Subsequent phenotypic studies have failed to support a link between this isozyme and PD. Similarly, the most extensive genetic studies initially confirmed this link, but a critical analysis of the recent studies from different groups again failed to draw any definitive conclusion (Riedl et al., 1998). Indeed, with respect to CYP 2D6, no laboratories have succeeded in replicating the initial report of Smith et al. (1992), according to which the frequency of poor metabolizers significantly increased in a PD population. Subsequent reports have been conflicting, although some groups have claimed differences in the allelic frequency of CYP 2D6*4 and other CYP 2D6 allelic variants in PD. Two recent meta-analyses failed to find an increased frequency of poor metabolizers among PD patients (Christensen et al., 1998; Rostami-Hodjegan et al., 1998). On the contrary, an earlier meta-analysis suggested a weak association, but this included fewer studies (McCann et al., 1997). As a result of their inability to observe any association, other authors performed sub-group analyses, thus suggesting a possible link with "young onset PD" (Agundez et al., 1995) or PD with prominent tremor (Akhmedova et al., 1995). Unfortunately, these findings have not been replicated, either (Sandy et al., 1996). Although most studies have been negative, there are some critical issues that have been addressed by Le Couteur and McCann (1998) in connection with this problem. First, it is unlikely, on the basis of current studies, to completely refute the involvement of CYP 2D6, as, in order to have a definitive study of a statistical power, one would need almost 3000 subjects to exclude a 50\% increase in the frequency of poor metabolizers among PD patients. The second issue is that studies should consider only patients who have had neurotoxin exposure. If CYP 2D6 polymorphism influences vulnerability to PD by affecting the metabolism of an environmental neurotoxin, then studies should include only those subjects who have undergone this kind of neurotoxin exposure. The authors concluded that this stratification for toxin exposure is necessary in order to rule out the role of CYP 2D6 in the pathogenesis of PD.

This last concept of an environmental toxin and CYP 2D6, as its metabolizing enzyme, opens an old issue regarding the toxic hypothesis of PD, which originated from the incidental discovery of MPTP as a widespread impurity (Langston et al., 1983). Indeed, MPTP is metabolized by some P450 enzymes and by CYP 2D6 in particular (Coleman et al., 1996; Gilham et al., 1997) and has recently been discovered to be a synthetic impurity of heterocyclic drugs (Kramer et al., 1998). In this study, the authors assessed the risk of administering MPTP orally and reported that compounds containing less than 5 p.p.m. of MPTP do not involve any neurotoxicological health risk. They concluded surprisingly that it may be assumed that MPTP is also present as a yet undiscovered minor impurity in various existing drugs (Kramer et al., 1998). If this was true, MPTP or one of its analogues would represent the toxin probably responsible not for idiopathic $\mathrm{PD}$, but for a specific subgroup of parkinsonism. In this case, CYP 2D6-related metabolism would be of extreme importance and phenotypic and genotypic studies should be carried out on different and selected types of subjects.

\section{P450 IN EXPERIMENTAL PARKINSONISM}

In general, $\mathrm{MPP}^{+}$metabolism, unlike MPTP, has been poorly investigated. Johannessen et al. (1985) postulated that $\mathrm{MPP}^{+}$ may be transformed into free radical species, and other authors provided evidence for CYP 2D isoform involvement (FonnePfister and Meyer, 1988; Jolivalt et al., 1995). It is interesting to note that CYP 2E1 is associated with the metabolism of several small planar molecules, such as nitrosoamines, benzene, alcohol and 3-hydroxypiridine (Parkinson, 1996), and is present in a functional form because its levels can be induced by prior treatment with isoniazid (Park et al., 1993). CYP 2E1 therefore may represent, in this particular case, a detoxification pathway of $\mathrm{MPP}^{+}$, whose inhibition by DDC leads to an increased toxicity. A similar conclusion can be drawn for CYP 2D isozymes. CYP 2D6, the isoform present in humans and monkeys, metabolizes MPTP and $\mathrm{MPP}^{+}$probably to harmless compounds (FonnePfister and Meyer, 1988; Jolivalt et al., 1995; Coleman et al., 1996; Gilham et al., 1997). Therefore, "CYP 2D6 poor metabolizers," or the drugs that inhibit this isoenzyme, may represent susceptible factors favoring the neurotoxicity induced by MPTP (Barbeau et al., 1985; Lane, 1998). It is worth noting that $\mathrm{MPP}^{+}$ binding sites, as described by Del Zompo et al. (1986), may partly correspond in the mouse brain to the substrate recognition sites of CYP 2D isozymes. This $\mathrm{MPP}^{+}$binding, indeed, is displaced potently by debrisoquine and its analogues, which are good substrates for the P450 system (Del Zompo et al., 1990). $\mathrm{MPP}^{+}$binding has also been studied in post-mortem brain of PD patients and, among the several brain areas analyzed, only the Substantia Nigra (SN) showed a reduction in this binding in comparison with age-matched controls (Corsini et al., 1988). This reduction may be interpreted as a result of CYP 2D6 loss in the SN following DA neuron degeneration, a finding which is similar to that observed by Riedl et al. (1999) in the rat brain after 6-OHDA lesion of DA neurons. Furthermore, CYP 2D isoforms not only metabolize the neurotoxins MPTP and/or $\mathrm{MPP}^{+}$, but also markedly participate in the metabolism of methamphetamine and its analogues (Lin et al., 1995). Actually, similar conclusions must be drawn for these toxic compounds which are widely abused by humans. The role of CYP 2D6-mediated metabolism of amphetamines must be considered not only for the hepatic enzyme, but also for the one present in DA neurons. At present, it is difficult to suggest the effective physiological role of this enzyme in the DA neuron. It is likely that it behaves like a guard against endogenous or exogenous harmful intruders (false transmitters) which may affect DA metabolism. The concept of a "false transmitter" implies that endogenous chemicals may be handled within the neurons like the natural transmitter, thereby influencing the intraneuronal disposition and release of the natural transmitter (Thoenen, 1969). Among the various false transmitters which affect DA neurons, tryptamine is one of the most widely studied (Baumgarten and Zimmermann, 1992). Tryptamine is an endogenous substrate of CYP 2D6 (Martinez et al., 1997) and its involvement in PD and in schizophrenia as well has been evaluated since the 60 's 
(Brune and Himwhich, 1962; Keuhl et al., 1968; Herkert and Keup, 1969; Smith and Kellow, 1969).

\section{CYTOCHROME P450 2E1}

The highest concentration of the enzyme CYP 2E1 is in the liver where it is the main P450 enzyme for ethanol metabolism (Thomas et al., 1987; de Waziers et al., 1990; Correa et al., 2009). However, it has been found in many extrahepatic organs, for example in kidney and lung. CYP 2E1 is specifically implicated in the metabolism of several compounds including toxicants and low molecular weight procarcinogens (Koop, 1992). Among the many endogenous substrates of the enzyme that have been identified (Ronis et al., 1996; Lieber, 1997; Ingelman-Sundberg, 2004), are ketones (e.g., acetone) and fatty acids such as arachidonic acid. The exogenous compounds metabolized by CYP 2E1 comprise a wide variety of xenobiotics (e.g., acetaminophen, aniline, paracetamol, N-nitrosodimetylamine, and chlorzoxazone, with the latter two often used as enzymatic probes), alcohols (e.g., ethanol, methanol), ACE, aromatic hydrocarbons such as benzene and toluene, halogenated hydrocarbons (e.g., carbon tetrachloride) and finally anesthetics including enflurane, isoflurane, and halothane. Its active site pocket is relatively small and hydrophobic, creating a suitable environment for small non-polar molecules. Due to its existence predominantly as high spin form, CYP 2E1 also is important in oxygen reduction and generation of reactive oxyradicals, potent initiators of membrane lipid peroxidation (Ekstrom and Ingelman-Sundberg, 1989; Persson et al., 1990).

Several isoenzymes of P450 have been identified in the CNS of several animal species, including man (Kalow, 1992; Warner et al., 1993). Altough the activities of the different cytocromes in the brain are very low as compared to in the liver, CYP 2E1 has been detected by immunohistochemical techniques in the DAcontaining areas, the striatum and the SN (Anandatheerthavarada et al., 1993a; Gonzalez and Kimura, 1999). As in the liver, CYP 2E1 in brain is inducible by, e.g., ethanol, isoniazid or nicotine administration (Anandatheerthavarada et al., 1993b; Sohda et al., 1993; Gonzalez and Kimura, 1999). Also, induction of this enzyme during ischemic injury was shown in hippocampal and cortex astrocytes of rat and gerbil in vivo (Tindberg et al., 1996; Watts et al., 1998) showed that inducible CYP 2E1 existed in the same compartment as tyrosine hydroxylase in the rat $\mathrm{SN}$ but could not detect the enzyme in nigral glia cells. In addition, localization of the enzyme in monkey brain, as well as prenatal and adult human brain was confirmed (Brzezinski et al., 1999; Upadhya et al., 2000; Joshi and Tyndale, 2006). The active form of CYP 2E1

\section{REFERENCES}

Agundez, J. A., Jimenez-Jimenez, F. J., Luengo, A., Bernal, M. L., Molina, J. A., Ayuso, L., et al. (1995). Association between the oxidative polymorphism and early onset of Parkinson's disease. Clin. Pharmacol. Ther. 57, 291-298. doi: 10.1016/0009-9236(95)90154-X

Akhmedova, S. N., Pushnova, E. A., Yakimovsky, A. F., Avtonomov,
V. V., and Schwartz, E. I. (1995). Frequency of a specific cytochrome P4502D6B (CYP2D6B) mutant allele in clinically differentiated groups of patients with Parkinson disease. Biochem. Mol. Med. 54, 88-90. doi: 10.1006/bmme.1995.1012

Ambhore, N. S., Antony, S., Mali, J. K., Kanhed, A. M., Bhalerao, A. R., and Bhojraj, S. (2012). Pharmacological has been found in ER (microsomes), in the Golgi apparatus and in the plasma membrane of rat hepatocytes (Wu and Cederbaum, 1992; Loeper et al., 1993; Neve et al., 1996). It is possible that in the CNS, the active form of this enzyme is localized in the same membrane compartments as its hepatic variety.

There is evidence that interindividual variability in the expression and functional activity of this cytochrome may be considerable. Genetic polymorphisms in CYP 2E1 were identified and linked to altered susceptibility to hepatic cirrhosis induced by ethanol and esophageal and other cancers in some epidemiological studies. Therefore, it is important to evaluate how such polymorphisms affect CYP 2E1 function and whether it is possible to construct a population distribution of CYP 2E1 activity based upon the known effects of these polymorphisms and their frequency in the population (Itoga et al., 2002; Danko and Chaschin, 2005).

Recently, considering these findings on the enzymatic properties and genetic characteristics of CYP 2E1 and the fact that the enzyme is found in the $\mathrm{SN}$, preliminary data demonstrated a possible association between CYP 2E1 polymorphisms and $\mathrm{PD}$ (Shahabi et al., 2009).

More recently Kaut et al. (2012) found decreased methylation of the cytochrome CYP 2E1 gene and increased expression of CYP 2E1 messenger RNA in PD patients' brains, suggesting that epigenetic variants of this cytochrome contribute to $\mathrm{PD}$ susceptibility. Alterations of gene methylation patterns may form an interface between genetic and environmental susceptibility, carrying forward long lasting changes which may have been acquired even in preceding generations (Feinberg, 2007; Suzuki and Bird, 2008; Urdinguio et al., 2009).

Summarizing the above mentioned paragraphs the use of ACE, or other CYP 2E1 substrates/inhibitors as well, revealed the role of a specific P450 enzyme in experimental parkinsonism as obtained in the MPTP mouse model. Similarly clinical studies in PD led to the conclusion that environmental factors, such as several xenobiotics, contribute to the development of the disease. Among the relevant toxic environmental chemicals, pesticides and volatile solvents are the most suspected ones which are all substrates of CYP 2E1. It is likely that the oxidative stress induced by these substrates, including ethanol and its main metabolite ACE, may trigger a chronic impairment of DA neurons leading to degeneration. CYP 2E1 epigenetic alterations may facilitate the degenerative process through the metabolism of such xenobiotics and represent the genetic susceptibility to the disease. CYP 2E1 might be just the tip of the iceberg of epigenetic alterations to be identified in apparently sporadic neurodegenerative disorders. and biochemical interventions of cigarette smoke, alcohol and sexual mating frequency on idiopathic rat model of Parkinson's disease. J. Young Pharm. 3, 177-183.

Anandatheerthavarada, H. K., Shankar, S. K., Bhamre, S., Boyd, M. R., Song, B. J., and Ravindranath, V. (1993a). Induction of brain cytochrome P-450IIE1 by chronic ethanol treatment. Brain Res. 601, 279-285. doi: 10.1016/0006-8993 (93)91721-4

Anandatheerthavarada, H. K., Williams, J. F., and Wecker, L. (1993b). Differential effect of chronic nicotine administration on brain cytochrome P4501A1/2 and P4502E1. Biochem. Biophys. Res. Commun. 194, 312-318. doi: 10.1006/bbrc.1993.1821 
Barbeau, A., Cloutier, T., Roy, M., Plasse, L., Paris, S., and Poirier, J. (1985). Ecogenetics of Parkinson's disease: 4-hydroxylation of debrisoquine. Lancet 2, 1213-1216.

Baumgarten, H. G., and Zimmermann, B. (1992). "Neurotoxic Phenylalkylamines and Indolealkylamines," in Selective Neurotoxicity. Handbook of Experimental Pharmacology, Vol. 102, Ch VIII, eds H. Herken and F. Hucho (Berlin Heidelberg: Springer-Verlag), 225-291.

Benedetti, M. D., Bower, J. H., Maraganore, D. M., McDonnell, S. K., Peterson, B. J., Ahlskog, J. E., et al. (2000). Smocking, alcohol, and coffee consumption preceding Parkinson's disease: a case-control study. Neurology 55, 1350-1358. doi: 10.1212/WNL.55.9.1350

Bennet, P., Ramsden, D. B., Williams, A. C., and Ho, S. L. (1994). Cytochrome P450 1A1 (CYP1A1) gene in familial and sporadic idiopathic Parkinson's disease (IPD). Mov. Disord. 9, 33.

Brune, G. G., and Himwhich, H. E. (1962). Indole metabolites in schizophrenic patients. Arch. Gent. Psychiatry 6, 324-328. doi: 10.1001/archpsyc. 1962.01710220066009

Brzezinski, M. R., Boutelet-Bochan, H., Person, R. E., Fantel, A. G., and Juchau, M. R. (1999). Catalytic activity and quantitation of cytochrome P-450 2E1 in prenatal human brain. J. Pharmacol. Exp. Ther. 289, 1648-1653.

Campdelacreu, J. (2012). Parkinson disease and Alzheimer disease: environmental risk factors. Neurologia. doi: $\quad$ 10.1016/j.nrl.2012.04.001. [Epub ahead of print].

Cashaw, J. L. (1993). Detremination of tetrahydropapaveroline in the urine of parkinsonian patients receiving L-dopa-carbidopa (Sinemet) therapy by high performance liquid chromatography. J. Chromatogr. 613, 267-273.

Charles, V., Boulin, S., and Gille, M. (2006). Wernicke's encephalopathy associated with chronic disulfiram intoxication. Rev. Neurol. 162, 1252-1256. doi: 10.1016/S0035-3787(06)75139-6

Christensen, P. M., Gotzsche, P. C., and Brosen, K. (1998). The sparteine/debrisoquine (CYP2D6) oxidation polymorphism and the risk of Parkinson's disease: a meta-analysis. Pharmacogenetics 8 , 473-479. doi: 10.1097/00008571199812000-00003

Coleman, T., Ellis, S. W., Martin, I. J., Lennard, M. S., and Tucker,
G. T. (1996). 1-Methyl-4-phenyl1, 2, 3, 6-tetrahydropyridine (MPTP) is $\mathrm{N}$-demethylated by cytochromes P450 2D6, 1A2 and 3A4-implications for susceptibility to Parkinson's disease. J. Pharmacol. Exp. Ther. 277, 685-690.

Collins, M. A. (2002). Alkaloids, alcohol and Parkinson's disease. Parkinsonism Relat. Disord. 8, 417-422. doi: 10.1016/S1353-8020(02)00024-X

Collins, M. A. (2004). Tetrahydropapaveroline in Parkinson's disease and alcoholism: a look back in honor of Merton Sandler. Neurotoxicology 25, 117-120. doi: 10.1016/S0161-813X(03)00145-1

Correa, M., Viaggi, C., Escrig, M. A., Pascual, M., Guerri, C., Vaglini, F., et al. (2009). Ethanol intake and ethanol-induced locomotion and locomotor sensitization in CYP2E1 knockout mice. Pharmacogenet. Genomics 19, 217-225. doi: 10.1097/FPC.0b013e328324e726

Corsini, G. U., Bocchetta, A., Zuddas, A., Piccardi, M. P., and Del Zompo, M. (1988). Covalent protein binding of a metabolite of 1-methyl-4phenyl-1, 2, 3, 6-tetrahydropyridine to mouse and monkey brain in vivo and in vitro. Biochem. Pharmacol. 37, 4163-4169. doi: 10.1016/00062952(88)90111-6

Corsini, G. U., Pintus, S., Chiueh, C. C., Weiss, J. F., and Kopin, I. J. (1985). 1-Methyl-4-phenyl-1,2,3,6tetrahydropyridine (MPTP) neurotoxicity in mice is enhanced by pretreatment with diethyldithiocarbamate. Eur. J. Pharmacol. 119, 127-128.

Corsini, G. U., Zuddas, A., Bonuccelli, U., Schinelli, S., and Kopin, I. J. (1987). 1-methyl-4-phenyl-1, 2, 3, 6-tetrahydropyridine (MPTP) neurotoxicity in mice is enhanced by ethanol or acetaldehyde. Life Sci. 40, 827-832. doi: 10.1016/00243205(87)90030-0

Danko, I. M., and Chaschin, N. A. (2005). Association of CYP2E1 gene polymorphism with predisposition to cancer development. Exp. Oncol. 27, 248-256.

Deehan, G. A., Jr, Brodie, M. S., and Rodd, Z. A. (2013). What is in that drink: the biological actions of ethanol, acetaldehyde, and salsolinol. Curr. Top. Behav. Neurosci. 13, 163-184. doi: 10.1007/7854_2011_198

De Lau, L. M., Giesbergen, P. C., De Rijk, M. C., Hofman, A., Koudstaal, P. J., and Breteler, M. M. (2004). Incidence of parkinsonism and Parkinson disease in a general population: the Rotterdam Study. Neurology 63, 1240-1244. doi: 10.1212/01.WNL. 0000140706.52798.BE

De Mari, M., De Biasi, R., Lamberti, P., Carella, E., and Ferrari, E. (1993). Unilateral pallidal lesion after acute disulfirtam intoxication: a clinical and magnetic resonance study. Mov. Disord. 8, 247-249. doi: 10.1002/mds.870080236

de Waziers, I., Cugnenc, P. H., Yang, C. S., Leroux, J. P., and Beaune, P. H. (1990). Cytochrome P 450 isoenzymes, epoxide hydrolase and glutathione transferases in rat and human hepatic and extrahepatic tissues. J. Pharmacol. Exp. Ther. 253, 387-394.

Del Zompo, M., Bernardi, F., Maggio, R., Piccardi, M., Johannessen, J. N., and Corsini, G. U. (1986). High affinity binding sites for 1-methyl-4-phenyl-pyridinium ion (MPP+) are present in mouse brain. Eur. J. Pharmacol. 129, 87-92. doi: 10.1016/0014-2999(86)90339-0

Del Zompo, M., Ruiu, S., Maggio, R., Piccardi, M. P., and Corsini, G. U. (1990). [3H]1-methyl-4phenyl-2, 3-dihydropyridinium ion binding sites in mouse brain: pharmacological and biological characterization. J. Neurochem. 54, 1905-1910. doi: 10.1111/j.14714159.1990.tb04889.x

Duncan, C., and Deitrich, R. A. (1980). A critical evaluation of tetrahydroisoquinoline induced ethanol preference in rats. Pharmacol. Biochem. Behav. 13, 265-281. doi: 10.1016/0091-3057(80)90083-0

Ekstrom, G., and Ingelman-Sundberg, M. (1989). Rat liver microsomal NADPH-supported oxidase activity and lipid peroxidation dependent on ethanol-inducible cytochrome P-450 (P-450IIE1). Biochem. Pharmacol. 38, 1313-1319. doi: 10.1016/0006-2952(89)90338-9

Evans, A. H., Lawrence, A. D., Potts, J., Appel, S., and Lees, A. J. (2005). Factors influencing susceptibility to compulsive dopaminergic drug use in Parkinson disease. Neurology 65, 1570-1574. doi: 10.1212/01.wnl. 0000184487.72289.f0

Factor, S. A., Weiner, W. J., and Hefti, F. (1989). Acetaminophen metabolism by cytochrome P450 monooxygenases in Parkinson's disease. Ann. Neurol. 26, 286-288. doi: 10.1002/ana.410260219

Feinberg, A. P. (2007). Phenotypic plasticity and the epigenetics of human disease. Nature 447, 433-440. doi: 10.1038/nature05919

Ferrari, M. D., Peeters, E. A., Haan, J., Roos, R. A., Vermey, P., De Wolff,
F. A., et al. (1990). Cytochrome P450 and Parkinson's disease. Poor parahydroxylation of phenytoin. J. Neurol. Sci. 96, 153-157. doi: 10.1016/0022-510X(90)90128-A

Fonne-Pfister, R., and Meyer, U. A. (1988). Xenobiotic and endobiotic inhibitors of cytochrome P-450dbl function, the target of the debrisoquine/sparteine type polymorphism. Biochem. Pharmacol. 37, 3829-3835. doi: 10.1016/0006-2952(88)90063-9

Fornai, F., Vaglini, F., Maggio, R., Bonuccelli, U., and Corsini, G. U. (1997). Species difference in the role of excitatory aminoacids in experimental parkinsonism. Neurosci. Biobehav. Rev. 21, 401-415. doi: 10.1016/S0149-7634(96)00042-5

Gesi, M., Santinami, A., Ruffoli, R., Conti, G., and Fornai, F. (2001). Novel aspect of dopamine oxidative metabolism (confounding outcomes take place of certainties). Pharmacol. Toxicol. 89, 217-224. doi: 10.1034/j.1600-0773.2001.d01151.x

Gilham, D. E., Cairns, W., Paine, M. J., Modi, S., Poulsom, R., Roberts, G. C., et al. (1997). Metabolism of MPTP by cytochrome P4502D6 and the demonstration of 2D6 mRNA in human foetal and adult brain by in situ hybridization. Xenobiotica 27, 111-125. doi: 10.1080/004982597240802

Gonzalez, F. J. (2007). The 2006 Bernard B. Brodie Award Lecture. Cyp2e1. Drug Metab. Dispos. 35, 1-8. doi: 10.1124/dmd.106.012492

Gonzalez, F. J., and Kimura, S. (1999). Role of gene knockout mice in understanding the mechanisms of chemical toxicity and carcinogenesis. Cancer Lett. 143, 199-204. doi: $\quad 10.1016 /$ S0304-3835(99) 00125-1

Gudjonsson, O., Sanz, E., Alvan, G. Aquilonius, S. M., and Reviriego, J. (1990). Poor hydroxylator phenotypes of debrisoquine and S-mephenytoin are not over-represented in a group of patients with Parkinson's disease. Br. J. Clin. Pharmacol. 30, 301-302. doi: 10.1111/j.13652125.1990.tb03780.x

Herkert, E. E., and Keup, W. (1969). Excretion patterns of tryptamine, indoleacetic acid, and 5-hydroxyindoleacetic acid, and their correlation with mental changes in schizophrenic patients under medication with alphamethyldopa. Psychopharmacologia 15, 48-59. doi: 10.1007/BF00410800 Hernan, M. A., Chen, H., Schwarzschild, M. A., and Ascherio, 
A. (2003). Alcohol consumption and the incidence of Parkinson's disease. Ann. Neurol. 54, 170-175. doi: 10.1002/ana.10611

Hernan, M. A., Logroscino, G., and Rodriguez, L. A. (2004). A prospective study of alcoholism and the risk of Parkinson's disease. J. Neurol. 7, 14-17.

Hipólito, L., Sánchez-Catalán, M. J., Martí-Prats, L., Granero, L., and Polache, A. (2012). Revisiting the controversial role of salsolinol in the neurobiological effects of ethanol: old and new vistas. Neurosci. Biobehav. Rev. 36, 362-378. doi: 10.1016/j.neubiorev.2011.07.007

Ingelman-Sundberg, M. (2004). Human drug metabolising cytochrome P450 enzymes: properties and polymorphisms. Naunyn Schmiedebergs Arch. Pharmacol. 369, 89-104. doi: 10.1007/s00210-003-0819-z

Irwin, I., Wu, E. Y., DeLanney, L. E., Trevor, L., and Langston, J. W. (1987). The effect of diethyldithiocarbamate on the biodisposition of MPTP: an explanation for enhanced neurotoxicity. Eur. J. Pharmacol. 141, 209-217. doi: 10.1016/00142999(87)90265-2

Itoga, S., Nomura, F., Makino, Y., Tomonaga, T., Shimada, H., Ochiai, T., et al. (2002). Tandem repeat polymorphism of the CYP2E1 gene: an association study with esophageal cancer and lung cancer. Alcohol. Clin. Exp. Res. 26, 15S-19S. doi: 10.1111/j.15300277.2002.tb02696.x

Johannessen, J. N., Kelner, L., Hanselman, D., Shih, M. C., and Markey, S. (1985). In vitro oxidation of MPTP by primate neural tissue: a potential model of MPTP neurotoxicity. Neurochem. Int. 7, 169-176. doi: 10.1016/0197-0186(85)90022-1

Jolivalt, C., Minn, A., Vincent-Viry, M., Galteau, M. M., and Siest, G. (1995). Dextromethorphan O-demethylase activity in rat brain microsomes. Neurosci. Lett. 187, 65-68. doi: 10.1016/0304-3940(95)11339-X

Jollow, D. J., Mitchell, J. R., Potter, W. Z., Davis, D. C., Gillette, J. R., and Brodie, B. B. (1973). Acetaminophen-induced hepatic necrosis. II. Role of covalent binding in vivo. J. Pharmacol. Exp. Ther. 187, 195-202.

Joshi, M., and Tyndale, R. F. (2006). Induction and recovery time course of rat brain CYP2E1 after nicotine treatment. Drug Metab. Dispos. 34, 647-652. doi: 10.1124/dmd.105.008029

Kalow, W. (1992). Pharmacoanthropology and the genetics of drug metabolis. Pharmacogenet. Drug Metab. Int. Encyclop. Pharmacol. 137, 865-877.

Kaut, O., Schmitt, I., and Wüllner, U. (2012). Genome-scale methylation analysis of Parkinson's disease patients' brains reveals DNA hypomethylation and increased mRNA expression of cytochrome P450 2E1. Neurogenetics 13, 87-91. doi: 10.1007/s10048-011-0308-3

Keuhl, F. A., Vanden-Heuval, W. J. A., and Ormond, R. E. (1968). Urinary metabolites in Parkinson's disease. Nature 217, 471-490.

Koop, D. R. (1992). Oxidative and reductive metabolism by cytochrome P450 2E1. FASEB J. 6, 724-730.

Kramer, P. J., Caldwell, J., Hofmann, A., Tempel, P., and Weisse, G. (1998). Neurotoxicity risk assessment of MPTP (N-methyl-4-phenyl-1, 2, 3, 6-tetrahydropyridine) as a synthetic impurity of drugs. Hum. Exp. Toxicol. 17, 283-293. doi: 10.1191/096032798678908648

Kurth, M. C., and Kurth, J. H. (1993). Variant cytochrome P450 CYP2D6 allelic frequencies in Parkinson's disease. Am. J. Med. Genet. 48, 166-168. doi: 10.1002/ajmg.1320480311

Lane, R. M. (1998). SSRI-induced extrapyramidal side-effects and akathisia: implications for treatment. J. Psychopharmacol. 12, 192-214. doi: 10.1177/0269881 19801200212

Langston, J. W., Ballard, P., Tetrud, J. W., and Irwin, I. (1983). Chronic parkinsonism in humans due to a product of meperidine-analog synthesis. Science 219, 979-980. doi: $10.1126 /$ science. 6823561

Laplane, D., Attal, N., Sauron, B., De Billy, A., and Dubois, B. (1992). Lesions of basal ganglia due to disulfiram neurotoxicity. J. Neurosurg. Psychiatry 55, 925-929. doi: 10.1136/innp.55.10.925

Le Couteur, D. G., and McCann, S. J. (1998). P450 enzymes and Parkinson's disease. Mov. Disord. 13, 851-852.

Lee, S. S., Buters, J. T., Pineau, T., Fernandez-Salguero, P., and Gonzalez, F. J. (1996). Role of CYP2E1 in the hepatotoxicity of acetaminophen. J. Biol. Chem. 271, 12063-12067. doi: 10.1074/jbc.271.20.12063

Lieber, C. S. (1997). Cytochrome P-4502E1: its physiological and pathological role. Physiol. Rev. 77, 517-544.

Lin, L. Y., Kumagai, Y., Hiratsuka, A., Narimatsu, S., Suzuki, T., Funae, Y., et al. (1995). Cytochrome
P4502D isozymes catalyze the 4-hydroxylation of methamphetamine enantiomers. Drug Metab. Dispos. 23, 610-614.

Loeper, J., Descatoire, V., Maurice, M., Beaune, P., Belghiti, J., Houssin, D., et al. (1993). Cytochromes P-450 in human hepatocyte plasma membrane: recognition by several autoantibodies. Gastroenterology 104, 203-216.

Marchitti, S. A., Deitrich, R. A., and Vasiliou, V. (2007). Neurotoxicity and metabolism of the catecholamine-derived 3, 4-dihydroxyphenylacetaldehyde and 3, 4-dihydroxyphenylglycolaldehyde: the role of aldehyde dehydrogenase. Pharmacol. Rev. 59, 125-150. doi: 10.1124/pr.59.2.1

Martinez, C., Agundez, J. A., Gervasini, G., Martin, R., and Benitez, J. (1997). Tryptamine: a possible endogenous substrate for CYP2D6. Pharmacogenetics 7 85-93. doi: 10.1097/00008571-1997 04000-00001

McCann, S. J., Pond, S. M., James, K. M., and Le Couteur, D. G. (1997). The association between polymorphisms in the cytochrome P-450 2D6 gene and Parkinson's disease: a casecontrol study and meta-analysis. J. Neurol. Sci. 153, 50-53. doi: 10.1016/S0022-510X(97)00179-2

Mitchell, J. R., Jollow, D. J., Potter, W. Z., Davis, D. C., Gillette, J. R., and Brodie, B. B. (1973). Acetaminophen-induced hepatic necrosis. I. Role of drug metabolism. J. Pharmacol. Exp. Ther.187, 185-194.

Neve, E. P., Eliasson, E., Pronzato, M. A., Albano, E., Marinari, U., and Ingelman-Sundberg, $\mathrm{M}$. (1996). Enzyme-specific transport of rat liver cytochrome P450 to the golgi apparatus. Arch. Biochem. Biophys. 333, 459-465. doi: 10.1006/abbi.1996.0415

Nissbrandt, H., Bergquist, F., Jonason, J., and Engberg, G. (2001). Inhibition of cytochrome P450 $2 \mathrm{E} 1$ induces an increase in extracellular dopamine in rat substantia nigra: a new metabolic pathway? Synapse 40, 294-301. doi: 10.1002/ syn. 1052

Noyce, A. J., Bestwick, J. P., SilveiraMoriyama, L., Hawkes, C. H., Giovannoni, G., Lees, A. J., et al. (2012). Meta-analysis of early nonmotor features and risk factors for Parkinson disease Ann. Neurol. 72, 893-901. doi: 10.1002/ana.23687

Paganini-Hill, A. (2001). Risk factors for Parkinson's disease: the leisure world cohort study.
Neuroepidemiology 20, 118-124. doi: 10.1159/000054770

Palacios, N., Gao, X., O'Reilly, E., Schwarzschild, M., McCullough, M. L., Mayo, T., et al. (2012). Alcohol and risk of Parkinson's disease in a large, prospective cohort of men and women. Mov. Disord. 27, 980-987. doi: 10.1002/mds.25050

Park, K. S., Sohn, D. H., Veech, R. L., and Song, B. J. (1993). Translational activation of ethanol-inducible cytochrome P450 (CYP2E1) by isoniazid. Eur. J. Pharmacol. 248, 7-14.

Parkinson, A. (1996). "Biotransformation of xenobiotics," in Toxicology: The Basic Science of Poison, 5th $E d n$, eds M. O. Klaassen, L. J. Casarett, and J. Doull (New York, NY: McGraw-Hill; San Francisco, CA: St. Louis), 113-186.

Peeters, E. A., Bloem, B. R., Kuiper, M. A., Vermeij, P., de Wolff, F. A., Wolters, E. C., et al. (1994). Phenytoin parahydroxylation is not impaired in patients with young-onset Parkinson's disease. Clin. Neurol. Neurosurg. 96, 296-299. doi: 10.1016/03038467(94)90117-1

Persson, J. O., Terelius, Y., and Ingelman-Sundberg, M. (1990). Cytochrome P-450-dependent formation of reactive oxygen radicals: isozyme-specific inhibition of P-450-mediated reduction of oxygen and carbon tetrachloride. Xenobiotica 20, 887-900. doi: 10.3109/00498259009046904

Riedl, A. G., Watts, P. M., Edwards, R. J., Schulz-Utermoehl, T., Boobis, A. R., Jenner, P., et al. (1999). Growth factor-2 expression in the rat brain by the atypical antipsychotic clozapine. Neuropharmacology 38, 1075-1082. doi: 10.1016/S00283908(99)00031-3

Riedl, A. G., Watts, P. M., Jenner, P., and Marsden, C. D. (1998) P450 enzymes and Parkinson's disease: the story so far. Mov. Disord. 13, 212-220. doi: 10.1002/mds.870130204

Ronis, M. J. J., Lindros, K. O., and Ingelman-Sundberg, M. (1996). The CYP2 Subfamily. ed C. Ioannides (Boca Raton, FL: CRC Press), 211-239.

Rostami-Hodjegan, A., Lennard, M. S., Woods, H. F., and Tucker, G. T. (1998). Meta-analysis of studies of the CYP2D6 polymorphism in relation to lung cancer and Parkinson's disease. Pharmacogenetics 8 227-238. doi: 10.1097/00008571199806000-00005

Sandy, M. S., Armstrong, M., Tanner, C. M., Daly, A. K., Di 
Monte, D. A., Langston, J. W., et al. (1996). CYP2D6 allelic frequencies in young-onset Parkinson's disease. Neurology 47, 225-230. doi: 10.1212/WNL.47. 1.225

Shahabi, H. N., Westberg, L., Melke, J., Håkansson, A., Belin, A. C., Sydow, O., et al. (2009). Cytochrome P450 2E1 gene polymorphisms/haplotypes and Parkinson's disease in a Swedish population. J. Neural Transm. 116, 567-573. doi: 10.1007/s00702-009-0221-1

Smith, C. A., Gough, A. C., Leigh, P. N., Summers, B. A., Harding, A. E., Maraganore, D. M., et al. (1992). Debrisoquine hydroxylase gene polymorphism and susceptibility to Parkinson's disease. Lancet 339, 1375-1377. doi: 10.1016/01406736(92)91196-F

Smith, I., and Kellow, A. H. (1969). Aromatic amines and Parkinson's disease. Nature 221, 1261. doi: $10.1038 / 2211261 \mathrm{a} 0$

Sohda, T., Shimizu, M., Kamimura, S., and Okumura, M. (1993). Immunohistochemical demonstration of ethanol-inducible P450 2E1 in rat brain. Alcohol Alcohol. Suppl. 1B, 69-75.

Steventon, G. B., Heafield, M. T., Waring, R. H., and Williams, A. C. (1989). Xenobiotic metabolism in Parkinson's disease. Neurology 39, 883-887. doi: 10.1212/WNL.39.7.883

Stott, I., Murthy, A., Robinson, A., Thomas, N. W., and Fry, J. R. (1997). Low-dose diethyldithiocarbamate attenuates the hepatotoxicity of 1,3-dichloro2-propanol and selectively inhibits CYP2E1 activity in the rat. Hum. Exp. Toxicol. 16, 262-266. doi: 10.1177/096032719701600505

Suzuki, M. M., and Bird, A. (2008). DNA methylation landscapes: provocative insights from epigenomics. Nat. Rev. Genet. 9, 465-476. doi: 10.1038/nrg2341

Takakubo, F., Yamamoto, M., Ogawa, N., Yamashita, Y., Mizuno, Y., and Kondo, I. (1996). Genetic association between cytochrome P450IA1 gene and susceptibility to Parkinson's disease. J. Neural Transm. Gen. Sect. 103, 843-849. doi: 10.1007/BF01273362
Thoenen, H. (1969). Bildung und funktionelle Bedeutung adrenerger Ersatztransmitter. Exp. Med. Pathol. Klin. 27, 1-85.

Thomas, P. E., Bandiera, S., Reik, L. M., Maines, S. L., Ryan, D. E., and Levin, W. (1987). Polyclonal and monoclonal antibodies as probes of rat hepatic cytochrome P-450 isozymes. Fed. Proc. 46, 2563-2566.

Tindberg, N., Baldwin, H. A., Cross, A. J., and Ingelman-Sundberg, M. (1996). Induction of cytochrome P450 2E1 expression in rat and gerbil astrocytes by inflammatory factors and ischemic injury. Mol. Pharmacol. 50, 1065-1072.

Tomas, M., Marin, M. P., MartinezAlonso, E., Esteban-Pretel, G., Diaz-Ruiz, A., Vasquez-Martinez, R., et al. (2012). Alcohol induces Golgi fragmentation in differentiated PC12 cells by deregulating Rab1-dependent ER-to-Golgi transport. Histochem. Cell Biol. 138, 489-501. doi: 10.1007/s00418-0120970-z

Tsuneoka, Y., Fukushima, K., Matsuo, Y., Ichikawa, Y., and Watanabe, Y. (1996). Genotype analysis of the CYP2C19 gene in the Japanese population. Life Sci. 59, 1711-1715. doi: 10.1016/S0024-3205(96)00507-3

Upadhya, S. C., Tirumalai, P. S., Boyd, M. R., Mori, T., and Ravindranath, V. (2000). Cytochrome P4502E (CYP2E) in brain: constitutive expression, induction by ethanol and localization by fluorescence in situ hybridization. Arch. Biochem. Biophys. 373, 123-134. doi: 10.1006/ abbi.1999.1477

Urdinguio, R. G., Sanchez-Mut, J. V., and Esteller, M. (2009). Epigenetic mechanisms in neurological diseases: genes, syndromes, and therapies. Lancet Neurol. 8, 1056-1072. doi: 10.1016/S14744422(09)70262-5

Vaglini, F., Fascetti, F., Tedeschi, D., Cavalletti, M., Fornai, F., and Corsini, G. U. (1996). Striatal MPP+ levels do not necessarily correlate with striatal dopamine levels after MPTP treatment in mice. Neurodegeneration 5, 129-136. doi: 10.1006/neur.1996.0019

Vaglini, F., Pardini, C., Viaggi, C., Bartoli, C., Dinucci, D., and Corsini, G. U. (2004). Involvement of cytochrome P450 2E1 in the 1-methyl-4-phenyl-1,2,3,6tetrahydropyridine-induced mouse model of Parkinson's disease. J. Neurochem. 2, 285-298. doi: 10.1111/j.1471-4159.2004.02720.x

Viaggi, C., Vaglini, F., Pardini, C., Caramelli, A., and Corsini, G. U. (2009). MPTP-induced model of Parkinson's disease in cytochrome P450 2E1 knockout mice. Neuropharmacology 56, 1075-1081. doi: 10.1016/j. neuropharm.2009.03.003

Villa, C., Pascual-Sedano, B. Pagonabarraga, J., and Kulisevsky, J. (2011). Impulse contyrol disorders and dopaminergic treatments in Parkinson's disease. Rev. Neurol. 167, 827-832. doi: 10.1016/j.neurol. 2011.01.018

Warner, M., Strömstedt, M., Wyss, A., and Gustafsson, J. A. (1993). Regulation of cytochrome P450 in the central nervous system. J. Steroid Biochem. Mol. Biol. 47, 191-194. doi: 10.1016/0960-0760(93)90074-7

Watts, P. M., Riedl, A. G., Douek, D. C., Edwards, R. J., Boobis, A. R., Jenner, P., et al. (1998). Co-localization of P450 enzymes in the rat substantia nigra with tyrosine hydroxylase. Neuroscience 86, 511-519. doi: 10.1016/S0306-4522(97)00649-0

Wirdefeldt, K., Adami, H. O., Cole, P., Trichopoulos, D., and Mandel, J. (2011). Epidemiology and etiology of Parkinson's disease: a review of the evidence. Eur. J. Epidemiol. 1, 51-58. doi: 10.1007/s10654-0119581-6

Wu, D., and Cederbaum, A. I. (1992). Presence of functionally active cytochrome P-450IIE1 in the plasma membrane of rat hepatocytes. Hepatology 15, 515-524. doi: 10.1002/hep.1840150326

Wu, K., Politis, M., and Piccini, P. (2009). Parkinson disease and impulse control disorders: a review of clinical features, pathophysiology and management. Postgrad. Med. J. 85, 590-596. doi: 10.1136/pgmj.2008.075820

Xiang, G., Honglei, C., Hyon, K. C., Curhan, G., Schwarzschild, M. A., and Ascherio, A. (2008). Diet, urate and Parkinson's disease risk in men. Am. J. Epidemiol. 167, 831-838. doi: 10.1093/aje/kwm385
Young-Joon, S., and Hyun-Jung, K. (2010). Neurotoxic effects of tetrahydroisoquinolines and underlying mechanisms. Exp. Neurobiol. 19, 63-70. doi: 10.5607/en.2010. 19.2.63

Zuddas, A., Corsini, G. U., Schinelli, S., Johannessen, J. N., Di Porzio, U., and Kopin, I. J. (1989a). MPTP treatment combined with ethanol or acetaldehyde destroys dopaminergic neurons in mouse substantia nigra. Brain Res. 501, 1-10. doi: 10.1016/0006-8993(89) 91020-2

Zuddas, A., Corsini, G. U., Schinelli, S., Barker, J. L., Kopin, I. J., and Di Porzio, U. (1989b). Acetaldehyde directly enhances MPP+ neurotoxicity and delays its elimination from the striatum Brain Res. 501, 11-22. doi: 10.1016/0006-8993(89) 91021-4

Zuddas, A., Vaglini, F., Fornai, F., and Corsini, G. U. (1992). Selective lesion of the nigrostriatali dopaminergic pathway by MPTP and acetaldehyde or diethyldithiocarbamate. Neurochem. Int. 20, 287S-293S. doi: 10.1016/0197-0186 (92)90254-O

Conflict of Interest Statement: The authors declare that the research was conducted in the absence of any commercial or financial relationships that could be construed as a potential conflict of interest.

Received: 20 March 2013; accepted: 01 June 2013; published online: 21 June 2013.

Citation: Vaglini F, Viaggi C, Piro V, Pardini C, Gerace C, Scarselli M and Corsini GU (2013) Acetaldehyde and parkinsonism: role of CYP450 2E1. Front. Behav. Neurosci. 7:71. doi: 10.3389/fnbeh.2013.00071

Copyright (c) 2013 Vaglini, Viaggi, Piro, Pardini, Gerace, Scarselli and Corsini. This is an open-access article distributed under the terms of the Creative Commons Attribution License, which permits use, distribution and reproduction in other forums, provided the original authors and source are credited and subject to any copyright notices concerning any third-party graphics etc. 